\title{
Mechanical properties balance in novel Z-pinned sandwich panels: - out-of-plane properties
}

\author{
Andrea I Marasco ${ }^{1}$, Denis D R Cartié ${ }^{1}$, Ivana K Partridge ${ }^{1}$ and Amir Rezai ${ }^{2}$ \\ ${ }^{1}$ School of Industrial and Manufacturing Science, Cranfield University, Bedford, UK, \\ ${ }^{2}$ BAE SYSTEMS ATC, Bristol, UK
}

\begin{abstract}
The paper presents the first complete set of test results obtained from quasi-static measurements of the out-of-plane tension, shear and compression properties of novel XCor $^{\mathrm{TM}}$ and $\mathrm{K}-\mathrm{Cor}^{\mathrm{TM}}$ flat sandwich panels. The cured panels were composed of $0.75 \mathrm{~mm}$ thick quasi-isotropic IM7/8552 skins, separated by $12.7 \mathrm{~mm}$ thick Rohacell ${ }^{\circledR}$ foam core containing $0.51 \mathrm{~mm}$ diameter carbon fibre pins (Z-Fiber $\left.{ }^{\circledR}\right)$, arranged in a truss pattern at pin angle of either $22^{\circ}$ or $30^{\circ}$ to the vertical. To obtain a suitable baseline comparison, the equivalent set of properties was measured for Nomex honeycomb core panels sandwiched by the same composite skins. The novel Z-pinned cores are found to exhibit higher specific stiffness than conventional sandwich cores, but lower strength.
\end{abstract}

Keywords List

$\mathrm{X}-\mathrm{Cor}^{\mathrm{TM}}$ - K-Cor ${ }^{\mathrm{TM}}$ sandwich structures; D-Mechanical testing; A-3-Dimensional reinforcement; A- Polymer-matrix composites (PMCs)

\section{INTRODUCTION}

\section{$\mathrm{X}-\mathrm{Cor}^{\mathrm{TM}}$ and $\mathrm{K}-\mathrm{Cor}^{\mathrm{TM}}$ sandwich panels}

These novel polymer composite structures consist of composite skins separated by a layer of Rohacell ${ }^{\circledR}$ foam into which Z-Fiber ${ }^{\circledR}$ pins (thereafter referred to as Z-pins) are 
inserted at a specific angle to form a truss. The version of Z-Fiber ${ }^{\circledR}$ used here is a cured pultruded carbon fibre/bismaleimide rod. Initially the pins inserted in the foam extend beyond each surface of the foam, for a so called "reveal length". The core at this stage is called a X-Cor ${ }^{\mathrm{TM}}$ preform (see Fig.1a). For the $\mathrm{X}-\mathrm{Cor}^{\mathrm{TM}}$ sandwich construction this preform is then pressed between two uncured composite skins, the pins enter into the surfacing prepreg plies and create a mechanical fastening between the core and the skin, without the need for any adhesive (see Fig.1b).

In the case of the $\mathrm{K}$-Cor ${ }^{\mathrm{TM}}$ preforms, the Z-pins which extend beyond the foam surface are only partially cured. They can therefore be folded back under the action of moderate heat and pressure, flush with the foam surface (see Fig.2). The required sandwich panel skins, which can be pre-cured composite or metallic plates, are then usually adhesively bonded onto the core. The additional heat supplied in the bonding process serves to complete the cure of the Z-pins. Further detail of the manufacturing processes involved in the production of the preforms can be found in a recent review [1]. The possibility of producing these preforms to net shapes and required pinning densities is attractive where complex sandwich construction is required [2]. The Rohacell ${ }^{\circledR}$ foam is a 'closed cell' type and is highly resistant to ingress by water. This confers a clear advantage to these sandwich panels in situations where water absorption and freeze-thaw cycles may otherwise present a problem.

\section{Out-of-plane properties of sandwich panels}

Relatively little experimental work has been carried out so far on the above described novel sandwich materials. The earliest published work by Vaidya and colleagues was prompted by considerations of whether these new materials could completely replace traditional honeycomb sandwich materials in aerospace applications and consequently it 
concentrated on their resistance to impact loading and compression after impact [3 - 6]. The basic conclusion was that the mechanical properties studied were strongly influenced by the angle at which the pins had been inserted into the foam core, with an angle of $10^{\circ}$ exhibiting better in out-of-plane indentation resistance than equivalent samples with insertion angle of $20^{\circ}$. In a later study O'Brien and Paris found the strength of the bond between the core and the skins to be the limiting factor under uniaxial tension, three-point bending and combined tension and bending loading conditions [7]. The work reported here was carried out in the context of considering a wide spectrum of applications for these sandwich structures; automotive and naval as well as aerospace. For this reason the emphasis was placed on obtaining basic quasistatic properties in the first instance and on their comparison to the response of Nomex honeycomb panels under equivalent modes of loading.

Data on the out-of-plane properties of a sandwich construction or of a type of core are required for design purposes. A sandwich structure is usually designed to bear out-ofplane shear stresses caused by bending moments acting on the skins. The overall bending deformation is dominated by the deformation of the skins while the core stabilises the faces against global and local buckling.

The out-of-plane tension test characterises primarily the strength of the core-skin interface. The out-of-plane shear test characterises the core behaviour as a part of the whole sandwich structure, as the skins play a minor part under this loading condition. The out-of-plane compression test determines the compression stiffness and strength of the core. It would be expected that the mechanical properties of the $\mathrm{X} / \mathrm{K}$-Cor ${ }^{\mathrm{TM}}$ products are mainly influenced by the Z-pin densities used, the pin insertion angle and the pin lay-out in the core. The angle of the pins in the truss will alter the balance 
between the shear and compression properties [1-2]. The testing reported here was carried out to explore and quantify this balance.

\section{MATERIALS AND METHODS}

Table 1 summarises the types of cores used in the study, together with their relevant attributes. The 'hollow' X-Cor and K-Cor were obtained by chemically removing the Rohacell foam, by a process which does not affect the Z-pins. These hollow cores were then combined with 6-ply skins of IM7 tape, prepregged with 8552 resin, in quasiisotropic lay-up configuration, and cured to a nominal final skin thickness of $0.75 \mathrm{~mm}$. The film adhesive used to co-cure the prepreg skins onto K-Cor preform was Redux 322 and a $180^{\circ} \mathrm{C}$ cure with a $120^{\circ} \mathrm{C}$ dwell was used.

In the tests in which the sandwich specimen facings were required to be bonded to other metal parts the adhesive used was Redux 420A Araldite and the best performance was obtained for 150 minute cure at $70^{\circ} \mathrm{C}$ under slight pressure. The surfaces to be glued were abraded with sandpaper and cleaned with acetone.

\section{Out-of-plane tension test}

The test was carried out according to ASTM C297 standard, the load being transmitted to the sandwich through thick loading blocks bonded to the sandwich skins. These loading blocks must be sufficiently stiff to keep the bonded facings flat under load. Accurate alignment of the specimen and of the fixtures is critical. The schematic of the test setup is shown in Fig.3. The tests were carried out at a constant crosshead speed of $0.5 \mathrm{~mm} / \mathrm{min}$. Failure of the bond between the loading blocks and the facings is not considered a valid failure for the purpose of this test. 
The out-of-plane tensile stress $\sigma$ is calculated by dividing the load $P$ by the effective area of the specimen $A_{\text {eff }}$ for the pinned cores (see Results and Discussion section) or by the original cross-sectional area for the Nomex. The elastic modulus is determined from the slope of the linear elastic portion of the load-extension curve. All the results presented here have been corrected for the compliance of the test machine and of the fixtures.

\section{Out-of-plane shear test}

The test method used, ASTM C 273, allows the determination of shear properties of sandwich constructions or cores, associated with shear distortion of planes parallel to the facings. As for other shear tests developed in recent years the objective is to maximise shear stress and minimise extraneous induced stresses in the specimen [8]. The test configuration does not produce a pure shear stress state in the specimen, but the specimen geometry is prescribed so as to minimise secondary stresses [9]. The test can be conducted on a core bonded directly to the loading plates or on the sandwich with its skins bonded to the plates. For the pinned cores the presence of the skins is necessary to guarantee representative constraint at pin ends. Fig.4 shows the fixture with all the main parts labelled. According to the test protocol the specimen should have a thickness equal to the thickness of the sandwich and a width not less than $50 \mathrm{~mm}$. The requirement on the length in order to minimize secondary stresses is to be at least 12 times the thickness and having the line of action of the direct tensile force passing through the diagonally opposite corners of the sandwich, as shown in Fig.4. The nominal dimensions chosen for the specimen are listed in Table 2. 
The load is applied at the ends of the rigid plates so as to distribute the load uniformly across the width of the specimen. According to reference [11], the shear strain is approximately uniform in the central part of the specimen, but it starts to decrease at a length of about one half of the core thickness from the free edges, where it becomes zero. The constant rate of movement of the cross head was set at $0.5 \mathrm{~mm} / \mathrm{min}$. The tensile shear plates are attached to the loading fixture with bolts. The relative displacements between the steel plates in both the longitudinal and the transversal directions were measured by two LVDTs positioned as close as possible to the centre lines of the specimen in order to limit the influence of the plate bending on the results [9].

The shear stress $\tau$ is calculated by dividing the load $P$ by the effective area $A_{\text {eff. }}$ For the Nomex specimens the effective area is simply the product of the length and the width of the specimen. The shear strain $\gamma$ and the shear modulus $G_{C}$ of the sandwich are calculated through:

$$
\begin{aligned}
& \gamma=\frac{\delta}{t_{C}} \\
& G_{C}=\frac{\tau}{\gamma}=\frac{P t_{C}}{\delta A_{\text {eff }}}
\end{aligned}
$$

where $\delta$ is the displacement or movement of one loading plate of the specimen with respect to the other, measured with an LVDT (see Fig. 4), $t_{C}$ the thickness of the specimen and $G_{C}$ is evaluated as the slope of the initial linear elastic portion of the $\tau-\gamma$ curve. 


\section{Out-of-plane compression test}

This test, performed according to the ASTM C365 standard, is used to determine the out-of-plane compressive strength and modulus and to investigate the failure mechanisms under this loading condition for a sandwich core. The quasi-static compression tests were conducted at a constant cross head speed of $0.5 \mathrm{~mm} / \mathrm{min}$ (corresponding to a nominal strain rate of $10^{-4} \mathrm{~s}^{-1}$ ) on sandwich specimens of nominal dimensions $40 \times 40 \mathrm{~mm}$.

\section{RESULTS AND DISCUSSION}

\section{Data analysis method for Z-pinned cores: load-bearing pin approach}

The determination of the effective cross-section area of the specimen $A_{\text {eff, }}$ which is used in the calculations of the out-of-plane stresses and moduli, is based on the actual number of load-bearing pins in each sample. A similar approach discounts any pins which are damaged and not correctly fastened to both skins from the calculation [12]. Such pins are usually found at the edges of the specimens (see Fig.5). The theoretical areal pin density $\rho_{t h}$ represents the theoretical number of load-bearing pins in a unit area and is determined as follows:

$$
\rho_{t h}=\frac{N_{t h}}{A_{\text {nom }}}
$$

Here $N_{\text {th }}$ is the number of Z-pins expected to be present in a given area $A_{\text {nom }}$ of perfect core, based on the manufacturer's specification. The effective pin areal density $\rho_{\text {eff }}$ is determined experimentally by identifying the effective load bearing pins $N_{\text {eff }}$ contained within the same nominal area $A_{\text {nom }}$ : 
$\rho_{\text {eff }}=\frac{N_{\text {eff }}}{A_{\text {nom }}}$

(NB. The value of $N_{\text {eff }}$ is determined by visual inspection of the specimen, discounting those pins not spanning across the two faces).

The effective area is then determined as follows:

$A_{e f f}=\frac{A_{n o m} \rho_{e f f}}{\rho_{t h}}$

The theoretical and effective pin densities for the specimens used are summarised in Table 2, indicating the extent of the edge effect in the different cases. Any edge effects in Nomex specimens are expected to be low enough to be neglected.

All the stress-strain curves presented, together with the values for strength and moduli, represent the material response based on a five test average, for each case considered. The tests were all displacement controlled.

\section{Out-of plane tension test results}

Figure 6 shows examples of stress-strain curves for Nomex, K-Cor $\left(30^{\circ}\right.$ pin angle $)$ and $\mathrm{X}$-Cor $\left(22^{\circ}\right.$ pin angle $)$ samples. The values for tensile strength and modulus obtained for the different types of sandwich are summarised in Table 3. There is relatively little difference between the modulus values of the K-Cor and X-Cor samples; both cases are above those measured for the Nomex samples. Measurements of the tensile strength, however, provide a much greater differentiation between the different materials. As might be expected, the strength of the $\mathrm{X}$-Cor with the $22^{\circ}$ pin angle is higher than that 
of $30^{\circ}$ pin angle X-Cor. For a fixed inclination of the pins $\left(30^{\circ}\right)$, the K-Cor exhibits superior performance to X-Cor under this mode of loading.

The observed differences in the absolute values of strength are accompanied by differences in the mechanisms of failure. In the case of Nomex the failure takes place only in the core as the cell walls of the honeycomb fail in tension (Fig 7a). For the pinned cores the skin-core interface is the critical part where the specimen fails. The strength of the X-Cor structures depends primarily on the ability of the pin to resist pullout from the skin (Fig.7b). In the case of the K-Cor structures, there are two principal skin-core bond mechanisms: - foam to skin bond and separate multiple bonds between the flattened pin surface and the skin (Fig.7c). It seems that this combination enhances the strength of K-Cor compared to X-Cor, nearly to the value obtained from the Nomex samples.

\section{Out-of-plane shear test results}

Examples of representative stress-strain curves obtained from shear loaded X-Cor, KCor and Nomex panels are shown in Fig. 8 and the averaged test results are summarised in Table 4. Direct comparison of X-Cor and K-Cor specimens containing pins inclined at $30^{\circ}$ shows that the main difference between the two core systems is the shear modulus: - for the same core and skin attributes the X-Cor is nearly twice as stiff as the K-Cor. Both are considerably stiffer that the Nomex panels. The K-Cor also exhibits a higher value of shear strength than the X-Cor, but the shear strength of the Nomex panel is almost double the best performance available from the Z-pinned core panels. The superior energy absorbing characteristics of the Nomex are evident from the stressstrain curves. 
The failure mechanisms of these different samples under shear loading are illustrated in Figs. 9a-c. For the pinned cores the dominant mode of failure is that of the core-skin interface, while for the Nomex specimens the failure is determined by the shear buckling of the honeycomb cell walls. For both X-Cor and K-Cor samples some Z-pin tip rotation is observed during the shear loading, accompanied by an incremental opening of the specimen. The other coexistent failure mechanism is pin pull out from the skin for the X-Cor and pin de-bond from the skin for the K-Cor specimen. However, in the case of the K-Cor, a shear failure of the foam is reached before the final failure. Shear cracks in the foam are clearly visible in Fig. 9a. This would suggest that the separate multiple bonds between the flattened pin surfaces and the skin in the K-Cor are stronger than the embedded pins, under shear loading.

The role of the foam in the X-Cor was investigated by out-of-plane shear tests on both standard X-Cor and hollow X-Cor characterised by a $22^{\circ}$ pin angle and $0.5 \mathrm{~mm} \mathrm{Z}$-pin diameter (see Tables 1 and 4 and Fig.10) and proved to be negligible. The shear strength of the foam alone was found to be about $0.4 \mathrm{MPa}$. This value corresponds to the post-failure plateau in the stress-strain curve of the K-Cor, shown in Fig.8.

\section{Out-of-plane compression test results}

The role of the foam was investigated further, by subjecting hollow K-Cor and hollow $\mathrm{X}$-Cor samples to compression. Unlike in shear, the role of the foam in now nonnegligible, especially in the K-Cor (see Fig. 11 and Table 5). This is not particularly surprising [13], as the foam is likely to act by delaying the pin buckling failure which would otherwise occur in unsupported pins subjected to compression - see Fig.12. The behaviour exhibited by both the $\mathrm{X} / \mathrm{K}$-Cor and by the $\mathrm{X} / \mathrm{K}$-Cor without foam is indicative of a buckling failure mechanism, observed in the testing and confirmed by 
the stress-strains diagrams. After an initial linear increase in the stress, there is a fairly sharp drop, followed by a collapse regime. As with the other modes of mechanical loading, Nomex exhibits higher strength but lower stiffness than the pin core sandwich panels.

\section{CONCLUSIONS}

For the set of materials used in this early study, manufacturing procedures and the range of test configurations employed, Nomex honeycomb sandwich panels outperformed the pinned-core sandwich panels in terms of ultimate strength. However, when the sandwich panel stiffness is the key design parameter, the choice of a pinned core would be appropriate. In a real application, the choice of core may also be influenced by the possible advantage of having a water ingress resistant foam core instead of a honeycomb core. If the absolute weight is the overriding issue, for the configuration of

the X-Cor sandwich panels tested, the Rohacell foam may be removed without a significant performance penalty, except for situations where compressive loads are likely to occur. The potential weight saving by foam removal can be close to $50 \%$.

From the above presented mechanical property data and failure investigations it would appear that the way in which the Z-pins anchor into the sandwich skins and how these pins tips react to applied stresses, is the critical failure determining factor. The failure processes are characterised by pin pull-out (in X-Cor), pin end debond (K-Cor) and, in shear, rotation of those pins which are opposed to the loading direction. It is the movement of these pin tips which determines the extent of the opening of the specimen during shear loading. 


\section{ACKNOWLEDGEMENTS}

The work was carried out through an EPSRC grant (GR/ R94305), aided by gift of raw materials from Aztex Inc. The authors are grateful for additional industrial support from BAE SYSTEMS.

\section{REFERENCES}

1. Partridge I K, Cartié D D R and Bonnington T. Manufacture and performance of Zpinned composites. Chapter 3 in: Advani $\mathrm{S}$ and Shonaike G, editors. Advanced Polymeric Materials: Structure-property relationships, CRC Press, 2003

2. Carstensen T, Cournoyer D, Kunkel E, Magee C. X-Cor Advanced Sandwich Core Material. In: Proceedings of 33rd International SAMPE Technical Conference. Seattle, WA, November, 2001

3. Vaidya U K, Kamath M V, Hosur M V, Haque A, Jeelani S. Low velocity and compression-after-impact response of pin-reinforced sandwich composites. American Society of Mechanical Engineers, Materials Division (Publication) MD, 1999; 86: 1-10

4. Vaidya U K, Kamath M V, Hosur M V, Jeelani S. Low-Velocity Impact Response of Cross-Ply Laminated Sandwich Composites with Hollow and Foam-Filled Z-Pin Reinforced Core. Journal of Composites Technology and Research, 1999; 21(2): 84-97 
5. Palazotto A N, Gummadi L N B, Vaidya U K and Herup E. LowVelocity Impact Damage Characteristics of Z-Fiber Reinforced Sandwich Panels-An Experimental Study. Composite Structures, 1999; 43(4): 275-288.

6. Vaidya U K, Palazotto A N, Gummadi L N B. Low velocity impact and compressionafter-impact response of Z-pin reinforced core sandwich composites. Journal of Engineering Materials and Technology, 2000; 122: 434-442

7. O'Brien K T, Paris I L. Exploratory investigation of failure mechanisms in transition regions between solid laminates and $\mathrm{X}-\mathrm{Cor}^{\mathrm{TM}}$ truss sandwich. Composite Structures 2002; 57: 189-204

8. Hodgkinson J M. Mechanical testing of advanced fibre composites. Woodhead Publishing and CRC Press. Cambridge, 2000

9. O'Connor D J. A comparison of test methods for shear properties of the cores of sandwich construction. Journal of Testing and Evaluation, 1989; 17(4): 241-246

10. Zenkert D. The handbook of sandwich construction. UK Engineering Materials Advisory Services Ltd and Chameleon Press Ltd. London, 1997

11. Grédiac M, Dufort L. Experimental evidence of parasitic effects in shear test on sandwich beams. Experimental Mechanics, 2002; 42: 186-193 
12. Cartié D D R, Fleck N A. The effect of pin reinforcement upon the throughthickness compressive strength of foam-cored sandwich panels. Comps Sci \& Tech 2003; 63: 2401-2409.

13. Kocher C, Watson W, Gomez M, Gonzalez I and Birman V. Integrity of sandwich panels and beams with truss-reinforced cores. Journal of Aerospace Engineering 2002; 15(3): 111-117

\section{FIGURE CAPTIONS}

Figure 1a - X-Cor ${ }^{\mathrm{TM}}$ preform and sandwich construction

Figure $1 \mathrm{~b}$ - Photograph of a cured X-Cor sample with woven fabric skins. The foam core thickness is $12.7 \mathrm{~mm}$.

Figure 2 - K-Cor ${ }^{\mathrm{TM}}$ preform and sandwich construction

Figure 3 - Tensile test fixture schematic

Figure 4 - Schematic of the shear test fixture, definition of $\delta$ and $\mathrm{t}_{\mathrm{C}}$ from [10]

Figure 5 - Edge effect, border pins

Figure 6 - Examples of Nomex, K-Cor $\left(30^{\circ}\right.$ pin angle $)$, X-Cor $\left(22^{\circ}\right.$ pin angle $)$ out-ofplane tension stress-strain curves

Figure $7 \mathrm{a}-$ Failure in Nomex core resulting from an out-of-plane tension test.

Figure $7 \mathrm{~b}$ - X-Cor specimen, tensile skin-core interface failure. The pins tend to pullout of the composite skin. 
Figure 7c-K-Cor specimen, tensile skin-core interface failure. Flattened pin ends have debonded from the top skin.

Figure 8 - Examples of Nomex, K-Cor $\left(30^{\circ}\right.$ pin angle $)$ and $\mathrm{X}$-Cor $\left(30^{\circ}\right.$ pin angle $)$ outof-plane shear stress-strain curves

Figure 9a - Failed K-Cor specimen

Figure 9b - Failed X-Cor specimen - close-up view

Figure 9c - Failed Nomex specimen - close-up view

Figure 10 - Comparison of X-Cor and hollow X-Cor ( $22^{\circ}$ pin angle) out-of-plane shear stress-strain curves

Figure 11 - Comparison of K-Cor and hollow K-Cor out-of-plane compression stressstrain curves

Figure 12 - Hollow X-Cor specimen subjected to compression loading, showing the buckling of the pins.

\section{TABLE CAPTIONS}

Table 1 Core attributes

Table 2 Specimen attributes

Table 3 Out-of-plane tension test results

Table 4 Out-of-plane shear test results 
Table 5 Out-of-plane compression test results

\section{FIGURES}

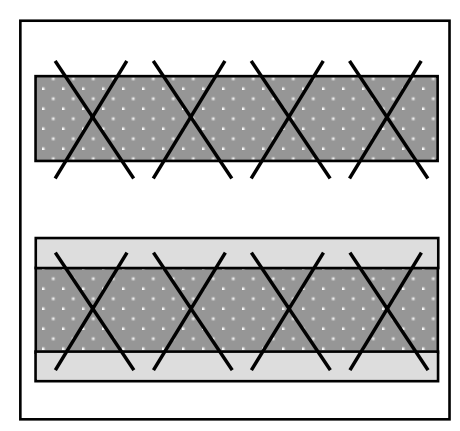

Figure 1a

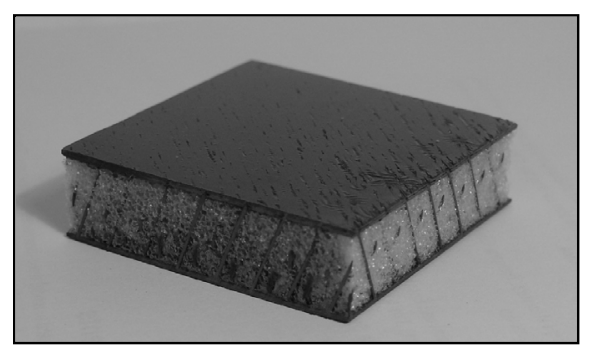

Figure 1b

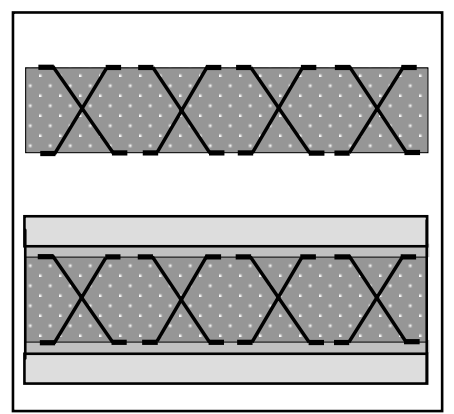

Figure 2 


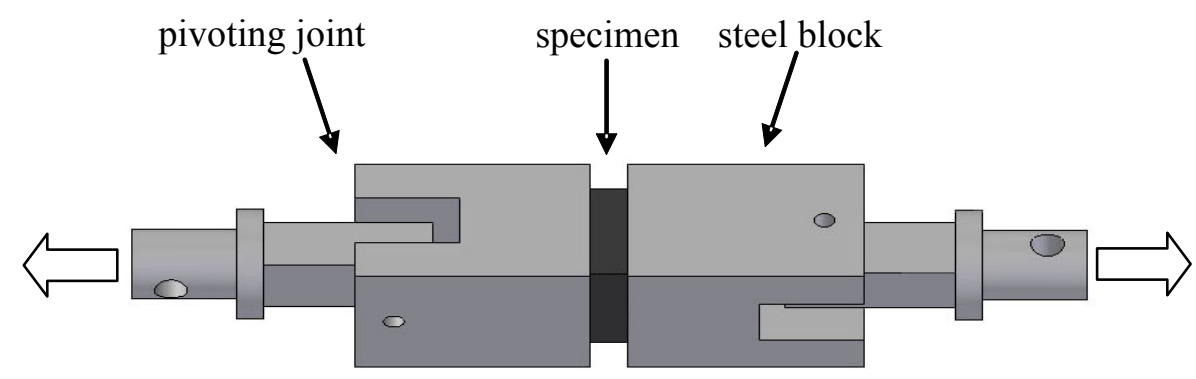

Figure 3

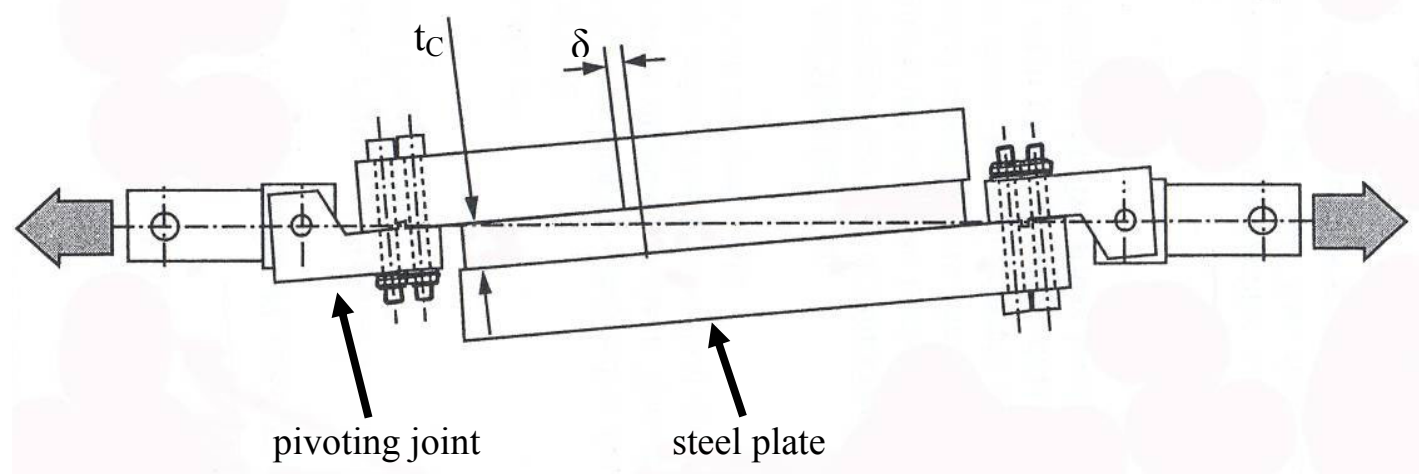

Figure 4 


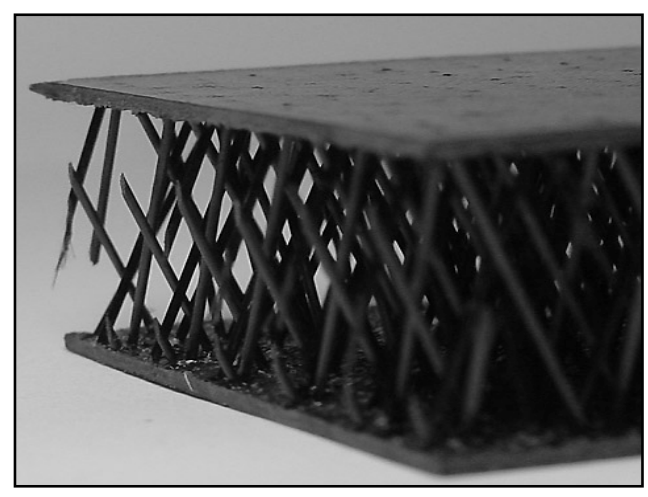

Figure 5

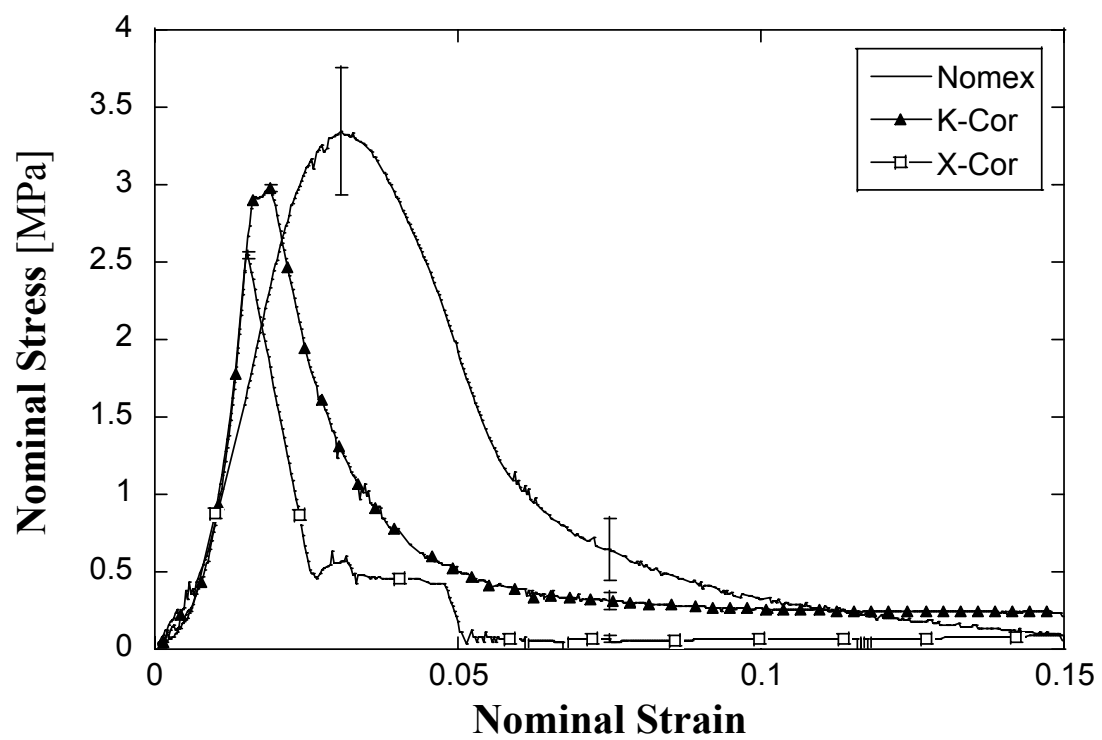

Figure 6

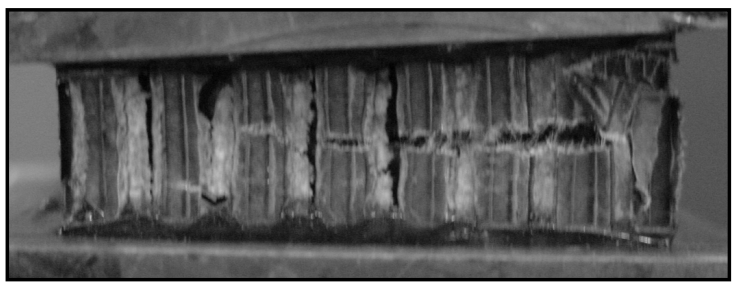

Figure $7 \mathrm{a}$ 


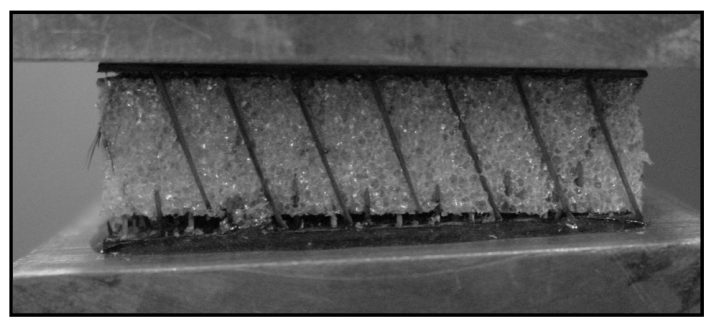

Figure $7 b$

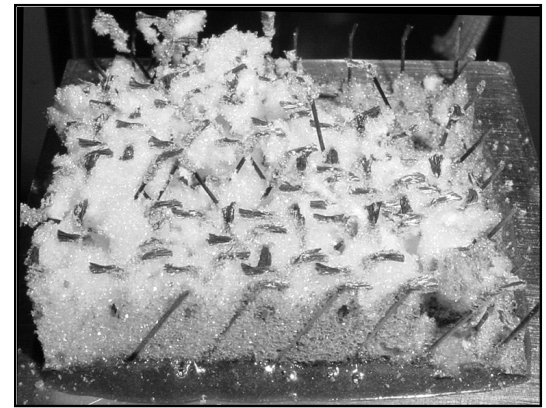

Figure $7 \mathrm{c}$

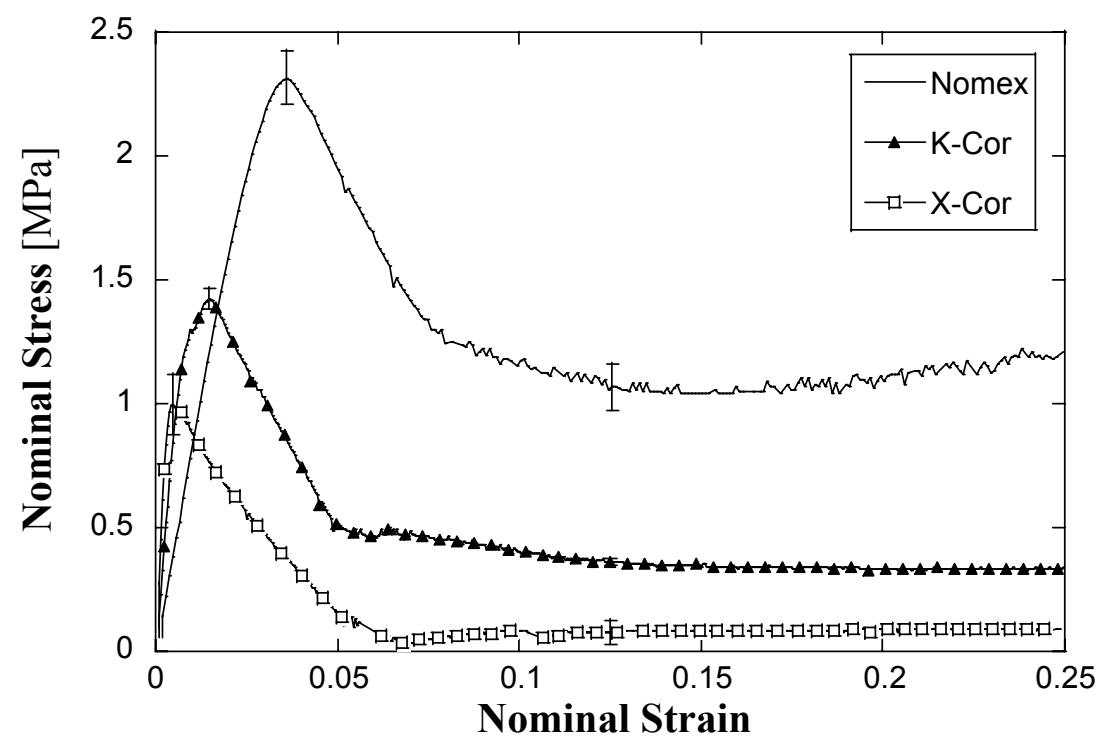

Figure 8 


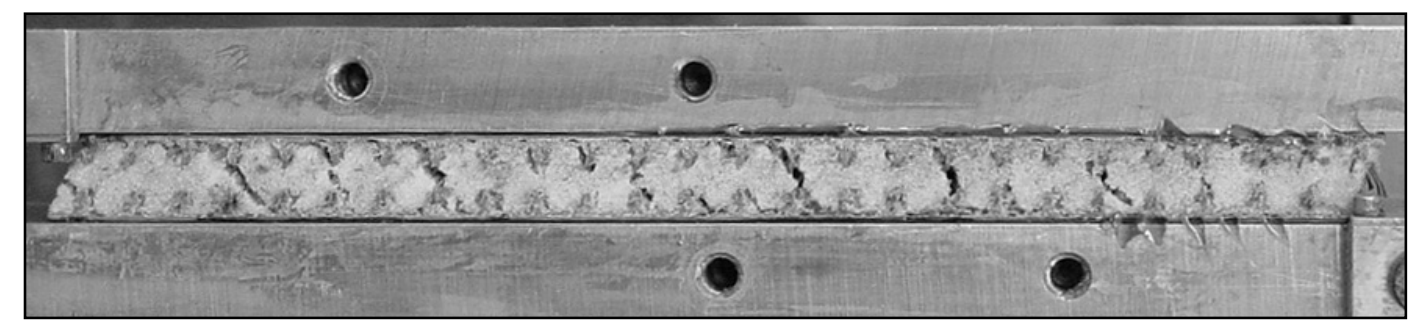

Figure 9a

Figure 9b
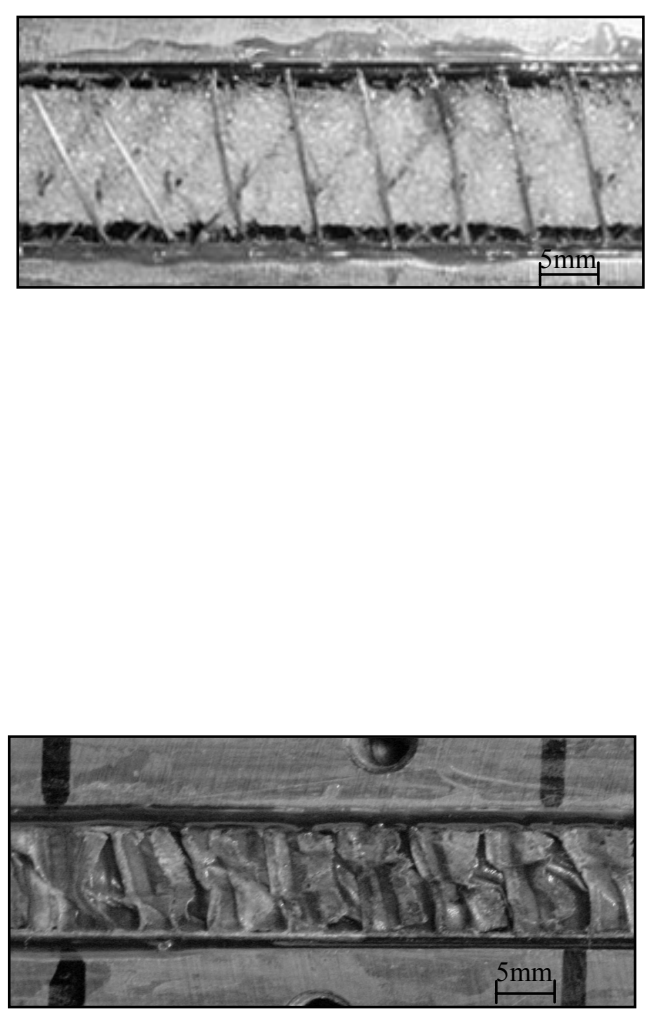

Figure 9c 


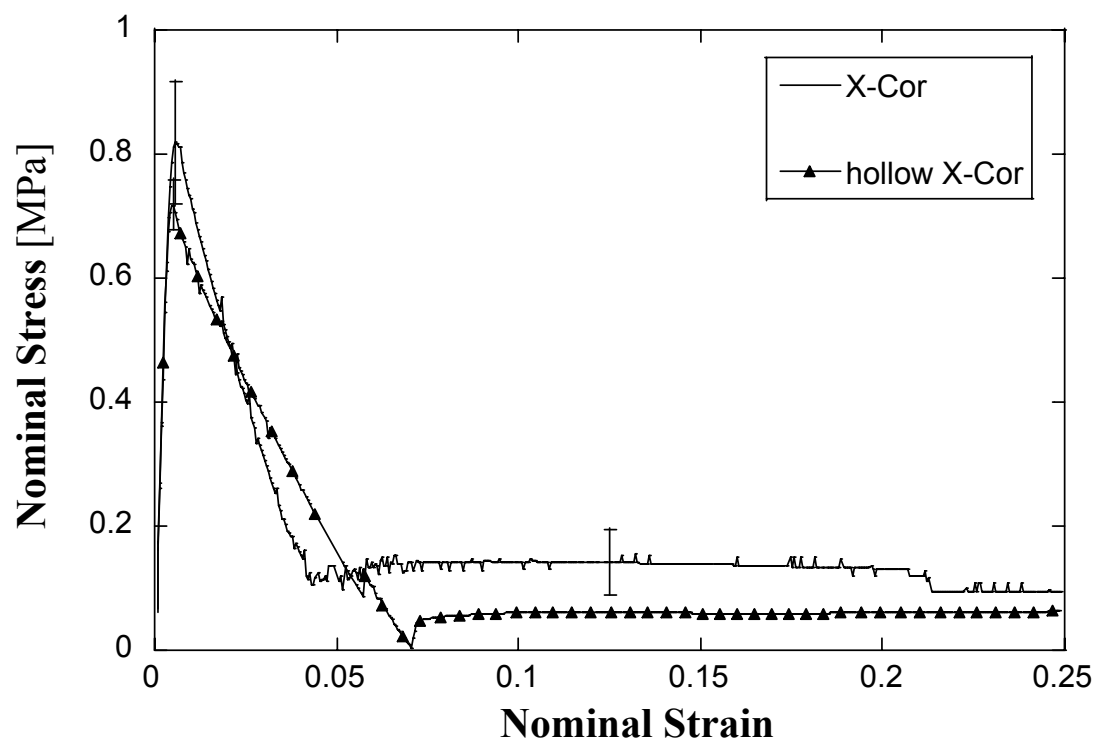

Figure 10

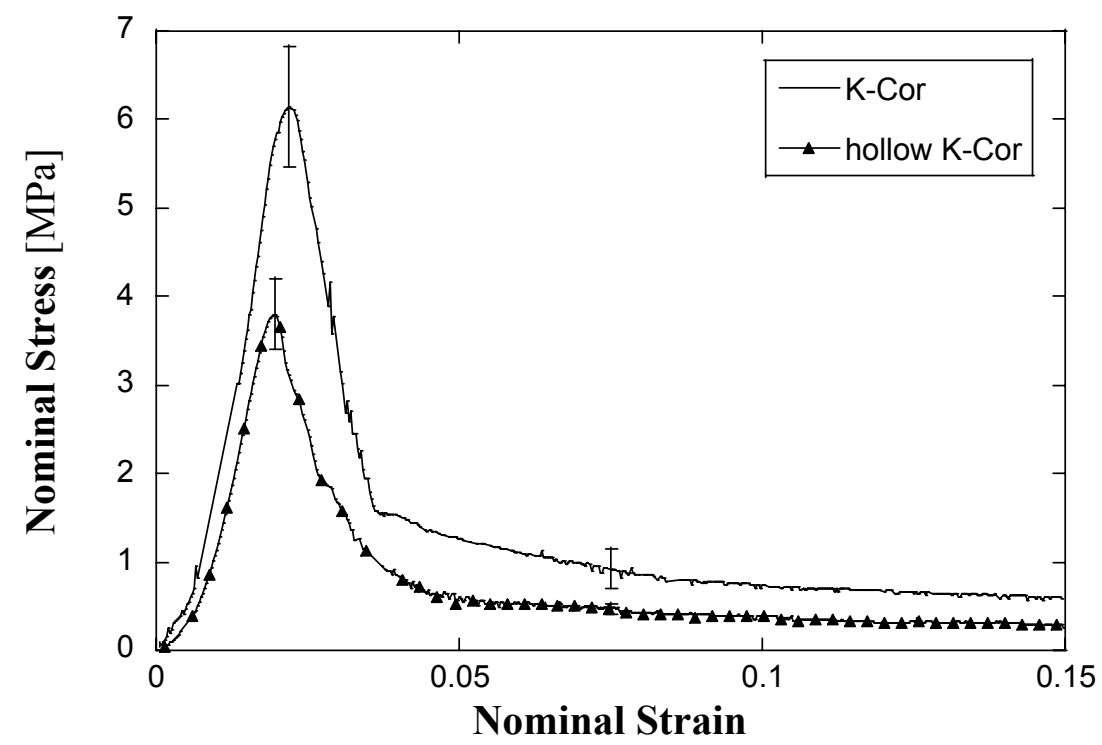

Figure 11 


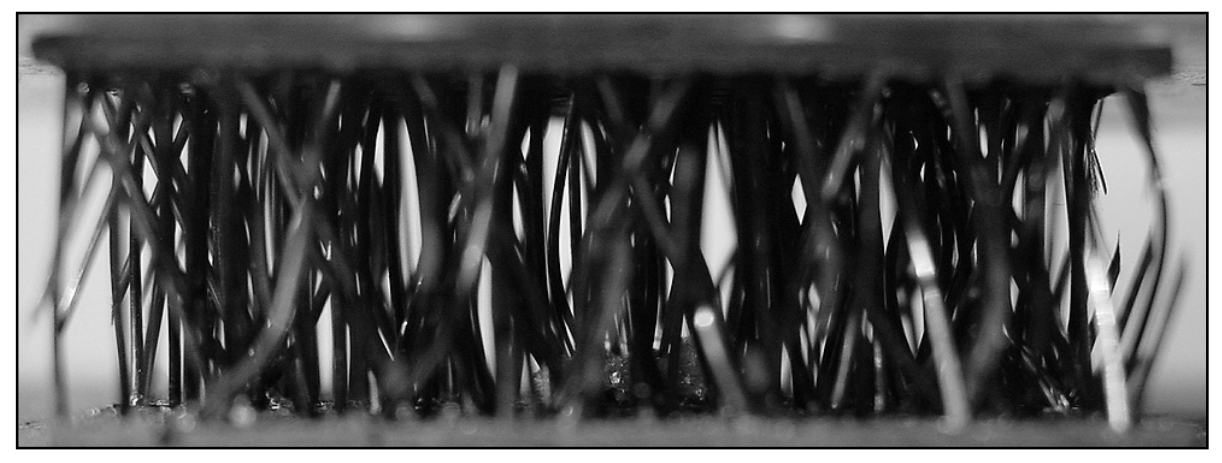

Figure 12 


\section{TABLES}

\begin{tabular}{ll}
\hline Core type & Attributes
\end{tabular}

\begin{tabular}{lcccccc}
\hline & thickness[mm] & density $\left[\mathrm{kgm}^{-3}\right]$ & cell face side[mm] & \multicolumn{2}{c}{ stabiliser } \\
\hline Nomex & 12.7 & 64 & \multicolumn{2}{c}{3.18} & \multicolumn{2}{c}{ Redux 322 } \\
\hline & thickness[mm] & density $\left[\mathrm{kgm}^{-3}\right]$ & pin Ø/fibre & pin angle \\
$\theta$ & & $\begin{array}{c}\text { foam } \\
\text { type }\end{array}$ & $\begin{array}{c}\text { foam density } \\
{\left[\mathrm{kgm}^{-3}\right]}\end{array}$ \\
\hline X-Cor type1 & 12.7 & $\sim 64$ & $0.51 / \mathrm{T} 300$ & $22^{\circ}$ & Rohacell & 32 \\
\hline X-Cor type 1 hollow & 12.7 & $\sim 32$ & $0.51 / \mathrm{T} 300$ & $30^{\circ}$ & - & - \\
\hline X-Cor type 2 & 12.7 & $\sim 64$ & $0.51 / \mathrm{T} 300$ & $30^{\circ}$ & Rohacell & 32 \\
\hline K-Cor & 12.7 & $\sim 64$ & $0.51 / \mathrm{T} 300$ & $30^{\circ}$ & Rohacell & 32 \\
\hline
\end{tabular}

Table 1

\begin{tabular}{|c|c|c|c|c|c|}
\hline & & & $\begin{array}{l}\text { out-of-plane } \\
\text { shear }\end{array}$ & $\begin{array}{l}\text { out-of-plane } \\
\text { tension }\end{array}$ & $\begin{array}{l}\text { out-of-plane } \\
\text { compression }\end{array}$ \\
\hline \multirow{2}{*}{$\begin{array}{l}\text { specimen nominal } \\
\text { dimensions }[\mathrm{mm}]\end{array}$} & & & $188 \times 50$ & $50 \times 50$ & $40 \times 40$ \\
\hline & $\alpha$ & $\begin{array}{c}\rho_{t h} \\
{\left[\mathrm{pin} / \mathrm{mm}^{2}\right]}\end{array}$ & $\rho_{\text {eff }} / \rho_{t h}$ & $\rho_{e f f} / \rho_{t h}$ & $\rho_{\text {eff }} / \rho_{t h}$ \\
\hline X-Cor type 1 & $22^{\circ}$ & 0.13 & 0.92 & 0.88 & 0.82 \\
\hline X-Cor type 2 & $30^{\circ}$ & 0.13 & 0.92 & 0.82 & 0.78 \\
\hline K-Cor & $30^{\circ}$ & 0.10 & 0.86 & 0.80 & 0.79 \\
\hline
\end{tabular}

Table 2

\begin{tabular}{ccccc}
\hline & $\begin{array}{c}\text { X-Cor } \\
\left(\theta=22^{\circ}\right)\end{array}$ & $\begin{array}{c}\text { X-Cor } \\
\left(\theta=30^{\circ}\right)\end{array}$ & $\begin{array}{c}\text { K-Cor } \\
\left(\theta=30^{\circ}\right)\end{array}$ & Nomex \\
\hline $\begin{array}{c}\text { out-of-plane } \\
\text { tensile strength } \\
{[\mathrm{MPa}]}\end{array}$ & $2.5 \pm 0.1$ & $1.6 \pm 0.4$ & $2.9 \pm 0.1$ & $3.3 \pm 0.4$ \\
\hline $\begin{array}{c}\text { out-of-plane } \\
\text { tensile modulus } \\
{[\mathrm{MPa}]}\end{array}$ & $350 \pm 27$ & $232 \pm 91$ & $398 \pm 50$ & $177 \pm 21$ \\
\hline
\end{tabular}

Table 3 


\begin{tabular}{cccccc}
\hline & $\begin{array}{c}\text { hollow X-Cor } \\
\left(\theta=22^{\circ}\right)\end{array}$ & $\begin{array}{c}\text { X-Cor } \\
\left(\theta=22^{\circ}\right)\end{array}$ & $\begin{array}{c}\text { X-Cor } \\
\left(\theta=30^{\circ}\right)\end{array}$ & $\begin{array}{c}\text { K-Cor } \\
\left(\theta=30^{\circ}\right)\end{array}$ & Nomex \\
\hline $\begin{array}{c}\text { Out-of-plane shear } \\
\text { strength [MPa] }\end{array}$ & $0.7 \pm 0.1$ & $0.8 \pm 0.1$ & $1.0 \pm 0.1$ & $1.4 \pm 0.1$ & $2.3 \pm 0.2$ \\
\hline $\begin{array}{c}\text { Out-of-plane shear } \\
\text { modulus [MPa] }\end{array}$ & $208 \pm 14$ & $200 \pm 25$ & $341 \pm 25$ & $176 \pm 9$ & $75 \pm 5$ \\
\hline
\end{tabular}

Table 4

\begin{tabular}{ccccccc}
\hline & $\begin{array}{c}\text { hollow } \\
\text { X-Cor } \\
\left(\theta=22^{\circ}\right)\end{array}$ & $\begin{array}{c}\text { X-Cor } \\
\left(\theta=22^{\circ}\right)\end{array}$ & $\begin{array}{c}\text { X-Cor } \\
\left(\theta=30^{\circ}\right)\end{array}$ & $\begin{array}{c}\text { hollow } \\
\text { K-Cor } \\
\left(\theta=30^{\circ}\right)\end{array}$ & $\begin{array}{c}\text { K-Cor } \\
\left(\theta=30^{\circ}\right)\end{array}$ & Nomex \\
\hline $\begin{array}{c}\text { out-of-plane } \\
\text { compression } \\
\text { strength [MPa] }\end{array}$ & $4.2 \pm 0.7$ & $5.0 \pm 0.5$ & $4.8 \pm 0.6$ & $3.8 \pm 0.4$ & $6.1 \pm 0.6$ & $6.9 \pm 0.9$ \\
\hline $\begin{array}{c}\text { out-of-plane } \\
\text { compression } \\
\text { modulus [MPa] }\end{array}$ & $403 \pm 83$ & $508 \pm 51$ & $428 \pm 40$ & $338 \pm 37$ & $441 \pm 83$ & $257 \pm 48$ \\
\hline
\end{tabular}

Table 5 